\title{
The Development of Creative Ecotourism Activities in the Botanical Garden in Ubon Ratchathani University
}

\author{
Khemchira Nongped ${ }^{1}$ and Suwaphat Sregongsang ${ }^{2}$ \\ ${ }^{1}$ Tourim Program, The Faculty of Liberal Arts, Ubon Ratchathani University \\ Email: Khemira26@gmail.com \\ ${ }^{2}$ Tourim Innovation Program, The Faculty of Liberal Arts, Ubon Ratchathani University \\ Email: Ajarntaes@gmail.com
}

\begin{abstract}
This research aims to investigate (1) the tourism resources of the botanical garden in Ubon Rachathani university, (2) the tourist's demands toward creative ecotourism activities in the botanical garden in Ubon Ratchathani university, (3) the created of creative ecotourism activities related to the tourists' demands in the botanical garden in Ubon Ratchathani university. This research was both qualitative and quantitative research. The researcher collected data by pilot testing 60 Thai tourists and interview 6 community headers related to the botanical garden. The results of the research was analyzed by descriptive analysis.

The results of the research found that the botanical garden with an area of 175 hectares are planted forests area and dry dipterocarp forest area. The resources in total, the interesting crop 106 species and animal 5 species. The results found that there were three creative ecotourismactivities that tourists demand; (1) ecosystem learning and local herbs (2) 1 tourists 1 tree and (3) educational nature trails. Therefore, in created the creative ecotourism activities in the botanical garden, those involved should study the popular ecotourism activities in current for adapt to the botanical garden area, and coupled with ecosystem conservation through the main process of ecotourism is learning, understanding and contribute to the awareness of the importance of natural resources. In conclusion, the creative ecotourism activities that could reach the tourist's demands; (1) Educational nature trails and (2) Cycling ecosystem learning, which popular ecotourism activities in current. Moreover, the interpretation is important factor with makes the tourists awareness of the importance of natu ral resources and contribute to the sustainable development of the area.
\end{abstract}

Keywords: ecotourism activities, creative tourism, botanical garden

\section{Introduction}

In the past, the original area of Ubon Ratchatni University was a National Reserved Forest for public benefit, especially the present Botanical Garden of Ubon Ratchathani University which is located on the east side of the university. This garden consists of two main forests, Raong Goa Forest and Nongnokkata Swamp Forest. These two forests still remain headwaters for natural streams including Nong-E-Gem Swamp (the water source of the university). These forest areas are considered aboriginal forests of the university with high biodiversity consisting of three main kinds of forests, dry evergreen forest, dry dipterocarp forest, and mixed deciduous forest. According to a reconnaissance survey, 45 families, 90 genus, and 100 kinds of plants were found. There are several species used as food and herbs, but unfortunately, some of them are endangered. (Wirot Kesonbua and Kaew Udomsirichakorn. 2013)

There are many kinds of plants from the North-Eastern region of Thailand found in this forest. Therefore, the forest of the university is comparable to natural and cultural forests which have various kinds of plants useful for the study of plant evolution, such as unicellular plants, ferns and fern allies, gymnosperm, and carnivorous plants. This forest also can be a natural library and a research and study source in the field of biodiversity for students and interested people. The ecotourism learning could promote the environmental conservation of people and lead to sustainable tourism. (Boonlert Jittangwattana. 2005)

\section{Objectives}

1. To investigate the tourism resources of the botanical garden in Ubon Rachathani university

2. To study the tourist's demands toward creative ecotourism activities in the botanical garden in Ubon Ratchathani university 
3. To create the creative ecotourism activities related to the tourists' demands in the botanical garden in Ubon Ratchathani University

\section{Research Methodology}

This research was the qualitative research by pilot testing 60 Thai tourists and interview 6 community headers related to the botanical garden. The results of the research was analyzed by descriptive analysis. The researcher conducted the pilot testing in order to collect the Thai tourists' demands towards the tourist activities. Besides the pilot testing, the researcher used interview as the research instruments to collect the data of tourism resources in the botanical garden. After taking pilot testing and collecting the tourists' demands towards the tourist activities in botanical garden, the researcher had presented the creative ecotourism activities related to the tourists' demands in the botanical garden in Ubon Ratchathani University. The researcher used the concept of ecotourism and creative tourism to analyze the data from pilot testing and interview.

\section{Results of the research}

\subsection{The Tourism Resources of the Botanical Garden in Ubon Rachathani University}

The botanical garden comprises of 175 hectares area. There are many natural resources in the botanical garden due to the data from interview six community headers such as the ecosystem in the swamp and the diversity of plants; Dipterocarpus intricatus Dyer, termite, Dipterocarpus obtusifolius Teijsm. Ex Miq, Tristaniopsis burmanica, scandent shrub, Gnetum, Eriocaulon, and Poaceae. Moreover, there are many kinds of wild animals such as poultries, insects, amphibians, reptiles and invertebrates. (Wirot Kesonbua and Kaew Udomsirichakorn. 2013)

\subsection{The Tourist's Demands toward Creative Ecotourism Activities in the Botanical Garden}

According to the results of the pilot testing from 60 Thai tourists, it finds that the tourists prefer the activities (1) to learn the ecosystem in the botanical garden, (2) to plant the local trees, (3) to study the natural trail and (4) to cycle. The description of the activities could be described as following;

\subsection{Learning the ecosystemin the botanical garden / studying the natural trail}

Learning activities on Botanical Garden forest ecosystems is an activity that encourages visitors to see the importance of forest ecosystems that is the rich natural resources and are important to local people . (Nirun Srinil. 2015. Interviewed) In the base, visitors could learn about the importance of ecosystems. (Kwankao Sungnakorn. 2015. Interviewed). It includes Hiking to study plants and wildlife, Learn about herbs, Taking advantage of the local people And conservation methods of Botanical Garden forest ecosystems. The distance of 3 kilometers and 12 learning base that composite;

\subsubsection{Pond Ecosystem: the complex relationships of organisms in the water.}

Pond ecosystem consists of living things and inanimate, such as aquatic plant, aquatic animals, temperature and oxygen dissolved in water etc. These elements are related to each other. These elements are related to each other. Through various processes, for example water evaporation, Photosynthesis and Food chain in the water cycle.
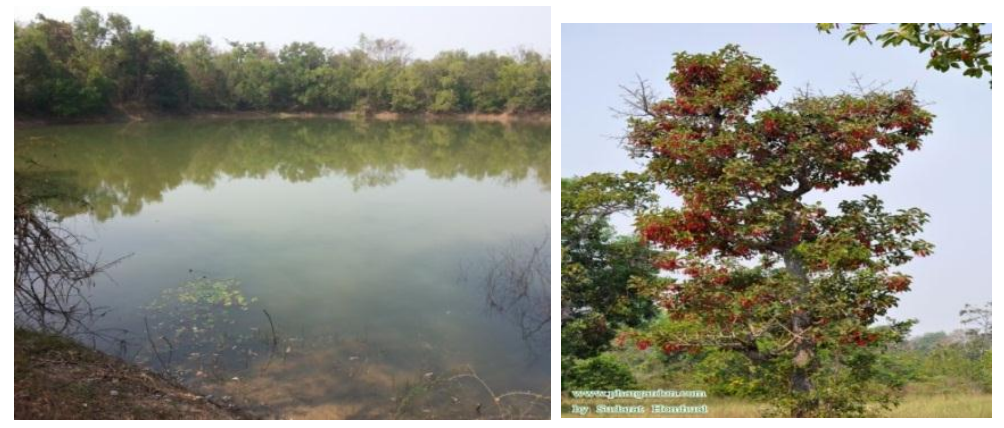

Picture 1-2: Pond Ecosystem (left) and Dominant tree Dry Dipterocarp Forest (right)

Source: (http://www.phargarden.com/main.php?action=viewpage \&pid=273) 


\subsubsection{Dipterocarpus intricatus: Dominant tree Dry Dipterocarp Forest}

Dipterocarpus intricatus is a common species of tree in the family Dipterocarpaceae. It's medium sized tree and able used for many things, for example a leaves use as roofing and wood used to make the contents of residential appliances.

\subsubsection{Termite: Life Cycle mound}

Termites have an important role in the decomposition of organic matter and plant debris fragments as nutrition. Considered helping them make the termite life cycle of the forest.
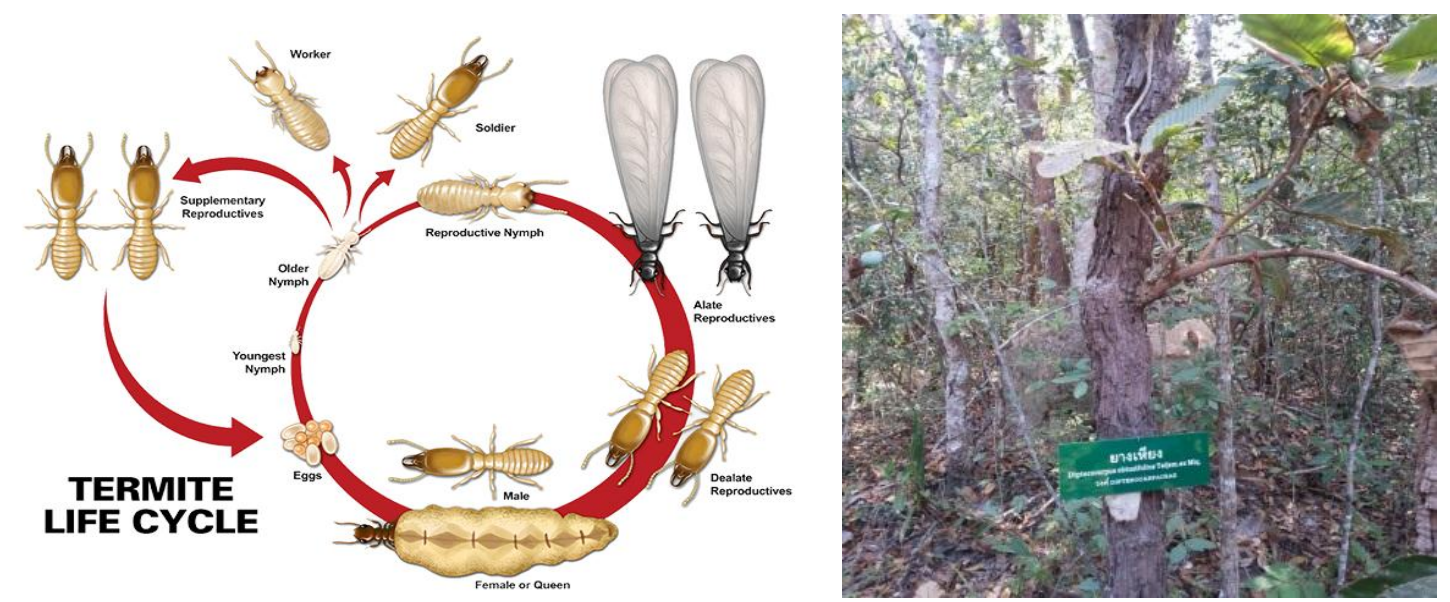

Picture 3-4: Termite life cycle (left) and Multifunction Plants (right)

Source: (http://www.termitenewyorkcity.com/mo re-about-termites/life-cycle)

\subsubsection{Dipterocarpus obtusifolius Teijsm: Multifunction Plants}

Dipterocarpus obtusifolius Teijsm is a common species of tree in the family Dipterocarpaceae. Trees are large, up to 30m tall, grow in dry Dipterocarp forest, the red brown wood is used in general construction, leaves use as food packaging and gum use to tinder.

\subsubsection{Tristaniopsis burmanica in the large jungle}

Tristaniopsis burmanica Peter G.Wilson \& J.T. Waterh. is a common in the Dry Dipterocarp Forest that found throughout Myanmar, Thailand, Cambodia, Laos and Vietnam. It's hardwood so the wood used to build a house.

\subsubsection{Ivy in Holt}

The growth of the stem above the ground, but mostly erect stems of plants that have changed shape and function. Some shrubs will be group if there isn't adhesion, but it is adhesion on, the trunk and branches along the trunk up to its adhesion. These plants are referred to as scandent shrub e.g. Willughbeia edulis Roxb and Aganosma maeginata (Roxb.) etc.

\subsubsection{We are Gnetum}

Gnetum sp. is a sticky bark so it used to rope, the trunk used boiled as an herbal remedy to treat a woman after childbirth and the seeds can be eaten. 


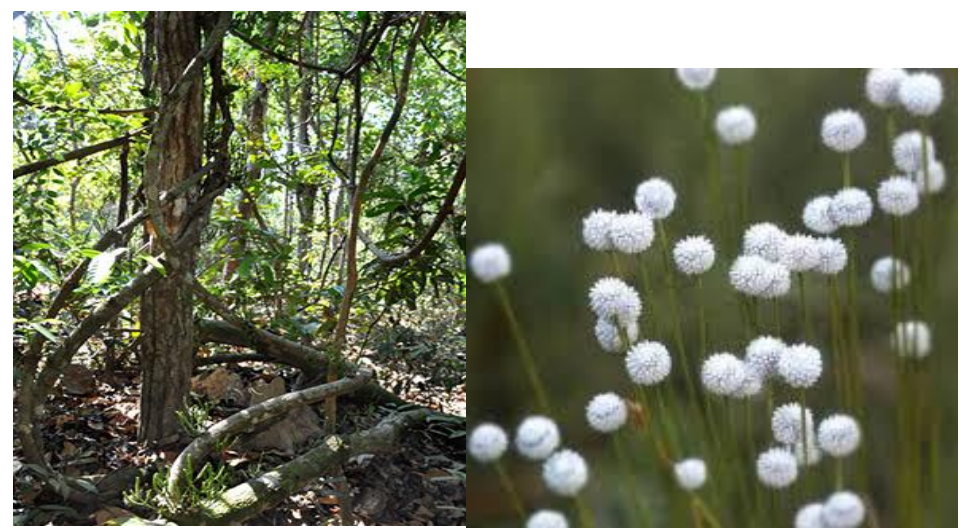

Picture 5-6: Gnetum sp. (left) and Eriocaulon sp. (right)

Source: http://travel.kapook.com/view137037.html

\subsubsection{Eriocaulon: the Angels on clay.}

Eriocaulon sp. is the plant that found in moist areas and open space. The flowers are white and bloom in the winter every year. So in the winter of each year Eriocaulon white blossom throughout the yard soil interspersed with colorful of plants, for example Utricularia bifida L. and U. delphininoides Thorel ex Pellegr. It is a natural beauty that still remains in Ubon Ratchathani University. Which is rare nowadays.

\subsubsection{Poaceae and Cyperaceae....The Similarities in differences}

The Poaceae is the large and nearly ubiquitous family of monocotyledonous flowering plants known as grasses. It has stems that are hollow except at the nodes and narrow alternate leaves borne in two ranks. The lower part of each leaf encloses the stem, forming a leaf-sheath

The Cyperaceae are a family of monocotyledonous graminoid flowering plants known as sedges, which superficially resemble grasses and rushes. Features distinguishing members of the sedge family from grasses or rushes are stems with triangular cross-sections (with occasional exceptions) and leaves that are spirally arranged in three ranks (grasses have alternate leaves forming two ranks)

\subsection{Planting the local trees}

Planting trees is an activity that allows visitors to contribute in increasing the forest botanical garden by planting one tree for each tree to increase the fertility of the ecosystem. (Piyaboot Harnwonsa. 2016). Interviewed). Forest areas that are the first people to travel from one tree planted forest area on the west side of the reservoir groove. And trees to be planted will be native vegetation. (Yuvadee Jitgosol. 2015. Interviewed)

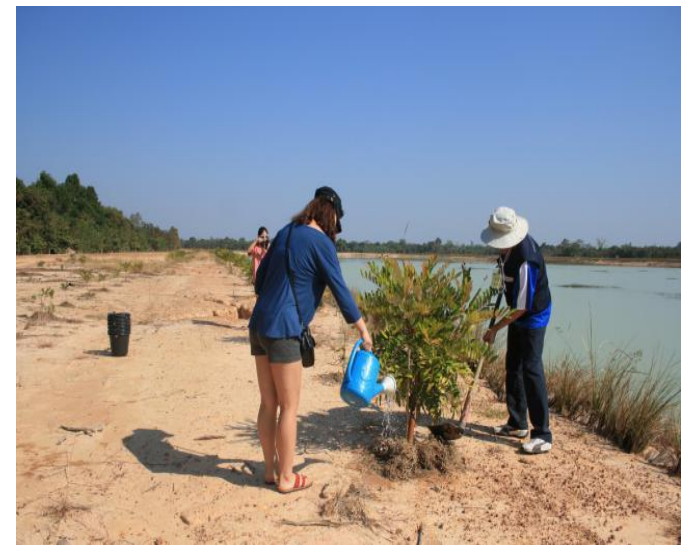

Picture 7: The activity for one tourist's one tree Source: www.bus.ubu.ac.th

Besides above activities that the Thai tourists prefer to join, there are two types of tourists activities could be conducted in the botanical garden. There are one tourists one tree and cycling for ecosystem learning. 


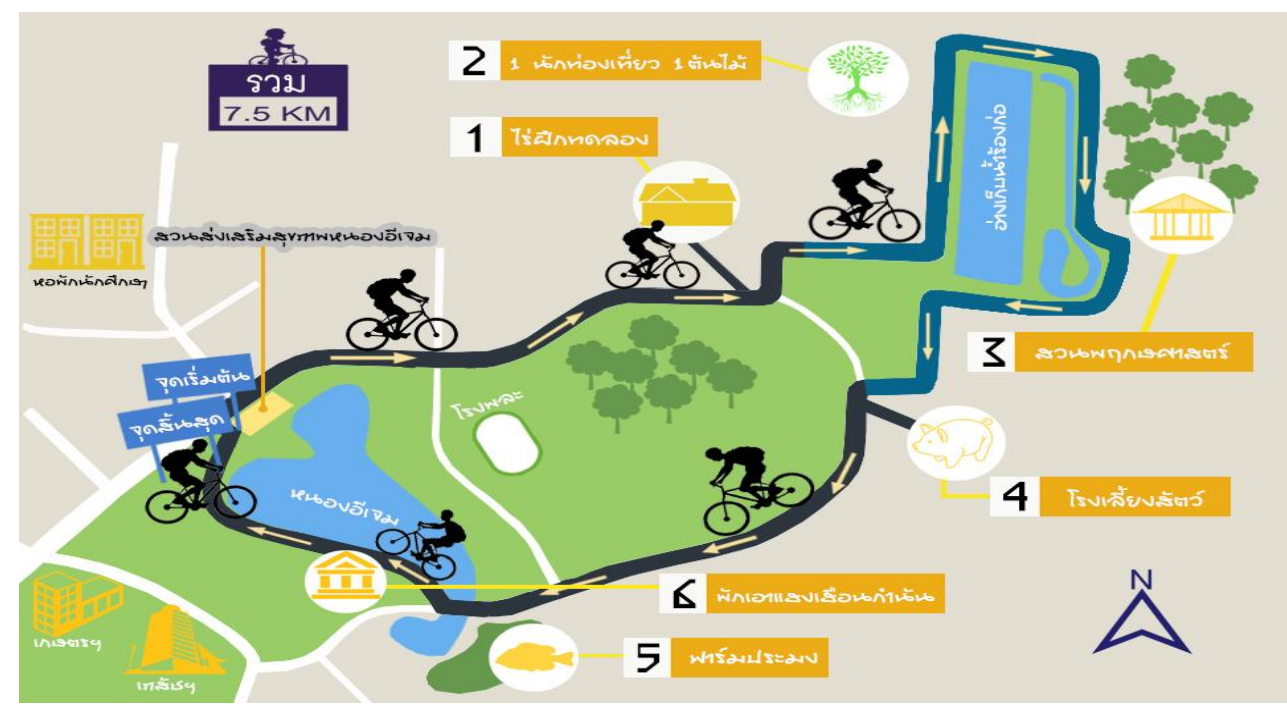

Picture 8: The cycling route for ecosystem learning

\section{Discussion and Conclusion}

The researcher used the concept of creative tourism from Greg Richards and Crispey Raymond (2000) to analyze and present the creative tourism activities in botanical garden in Ubon Ratchathani University. They define the concept of creative tourism as tourism which offers visitors the opportunity to develop their creative potential through active participation in courses and learning experiences which are characteristic of the holiday destination where they are undertaken. Due to above definition of the creative tourism, the research had presented five types of the creative tourism activities as follows: learning the ecosystem in the botanical garden, planting the local trees, studying the natural trail, one tourists one tree and cycling for ecosystem learning. All activities could support the tourist to participate, learn, and increase their experience about the ecosystem in the botanical garden in Ubon Ratchathani University. For example, the cycling for ecosystem learning the researcher had set six learning bases along the route in order to support the tourists to learn about the ecosystem inside the botanical garden and the other interesting sites in Ubon Ratchathani University. There are (1) planted farm, (2) one tourist one tree, (3) learning ecosystem in the botanical garden, (4) mammal farm, (5) fishery and (6) learning traditional house as in the picture 8 above.

\section{Suggestions from research}

The suggestions for creative tourism activities in Botanical garden in Ubon Ratchathani University were follows.

1. To create ecotourism activities in the botanical garden, those involved should develop the interpretation sings as well.

2. The stakeholders should participate for developing the creative tourism activities in the botanical garden.

3. The university should publish the creative ecotourism activities to the school in order to support ecosystem learning of the youth.

4. The university should assign the organization to response the creative ecotourism activities management for the tourists.

5. The university should provide the budget to develop the facilities in in the botanical garden such as toilets and the parking area.

\section{References}

[1] Jittangwattana, B. (2005). Tourism Development and Conservation. Bangkok: Press and Design Limited.

[2] Kesornbua, W. and Udomsirichakorn, K. (2013). Manual of Plant in botanical garden of Ubon 
a. Ratchathani University. Ubon Ratchathani: Ubon Ratchathani University.

[3] Kwankao Sungnakorn. The pilot testing tourist . [Interviewed: 21 Febuary, 2015].

[4] Nirun Srinil. 2015. The pilot testing tourist . [Interviewed: 21 Febuary, 2015].

[5] Piyaboot Harnwonsa. 2015. The pilot testing tourist . [Interviewed: 21 Febuary, 2015].

[6] Richards, G. and Raymond, C. (2000). Creative tourism. ATLAS News no.23. Tilburg University.

[7] Yuvadee Jitgosol. 2015. The pilot testing tourist . [Interviewed: 21 Febuary, 2015]. 